\title{
PEMANFAATAN TEKNOLOGI DALAM UPAYA MENGANTISIPASI MUSCULOSKELETAL DISORDERS (MSDS) PETANI DI KUBE USAHO BASAMO
}

\author{
Dessi Mufti $^{1{ }^{*}}$, Duskiardi ${ }^{2)}$, dan Mirza Zoni ${ }^{3)}$ \\ ${ }^{1)}$ Fakultas Teknologi Industri, Universitas Bung Hatta, email: dessimufti@bunghatta.ac.id \\ ${ }^{2)}$ Fakultas Teknologi Industri, Universitas Bung Hatta, email: duskiardi@bunghatta.ac.id \\ ${ }^{3)}$ Fakultas Teknologi Industri, Universitas Bung Hatta, email: Mirzazoni_ubh@yahoo.com
}

\begin{abstract}
ABSTRAK
Pertanian di Indonesia umumnya masih dilakukan secara sangat sederhana dengan mengandalkan tenaga manusia dan hewan. Jorong Koto Gadang merupakan daerah yang berpotensi untuk bercocok tanam holtikultura seperti tomat, cabe, kol, dan sayur-sayuran lainnya. Lahan yang tersedia lebih kurang seluas 20 ha, tetapi tergarap semua oleh masyarakat. ini disebabkan petani masih menggunakan peralatan manual (cangkul) untuk mengolah lahan yang ada. Selain itu pekerjaan mencangkul yang relatif lama akan dapat menyebabkan resiko cedera pada beberapa bagian anggota tubuh (Musculoskeletal Disorders/MSDs). Dirasakan sangat perlu memanfaatkan teknologi yang telah untuk memudahkan pekerjaan petani dan mengurangi resiko cedera tersebut. Berdasarkan asesmen awal dengan REBA diperoleh skor awal 10 artinya resiko levelnya sangat tinggi dan tindakan perbaikan perlu saat ini juga. Teknologi yang dapat digunakan adalah menggunakan cultivator. Pemilihan cultivator ini diperoleh dari diskusi dengan anggota Kube dengan melihat kondisi lahan dan fungsinya. Selanjutnya dilakukan asesmen kembali dengan REBA dan memperlihatkan hasil lebih baik dengan skor 7 yang artinya masih perlu perbaikan. Perbaikan dapat dilakukan dengan memodifikasi alat dan jenis material alat tersebut.
\end{abstract}

Kata Kunci: Ergonomi, Holtikultura, KUBE, Musculoskeletal disorders

\section{ABSTRACT}

Agriculture in Indonesia is generally still done very simply by relying on human and animal labor. Jorong Koto Gadang is an area that has the potential to grow horticulture such as tomatoes, chilies, cabbage, and other vegetables. The available land area is approximately 20 hectares, but it is cultivated by the community. this is due to farmers still using manual equipment (hoes) to cultivate existing land. In addition, relatively long hoeing work can cause the risk of injury to some parts of the body (Musculoskeletal Disorders / MSDs). It is felt that it is necessary to utilize technology that has made it easier for farmers to work and reduce the risk of injury. Based on the initial assessment with REBA an initial score of 10 means that the level of risk is very high and corrective action is necessary at this time. The technology that can be used is to use a cultivator. The selection of cultivators was obtained from discussions with Kube members by looking at the condition of the land and its functions. Furthermore, the assessment was carried out again with REBA and showed better results with a score of 7 which means it still needs improvement. Improvements can be made by modifying the tool and the type of material the tool is.

Keywords: Ergonomic, Holticultura, KUBE, Musculoskeletal disorders

\section{PENDAHULUAN}

Kelompok Usaha Bersama (KUBE)

Usaho Basamo ini terletak didaerah

pegunungan, sebagian besar masyarakatnya

adalah petani terutama pertanian holtikultura.
KUBE ini dibentuk untuk mendukung program pemerintah mengentaskan kemiskinan, meningkatkan kesejahteraan anggota khususnya dan masyarakat luas umumnya serta meningkatkan hasil produksi 
KUBE. Saat ini petani masih menggunakan peralatan manual yaitu cangkul dalam mengolah lahan anggota dan lahan Kube. Beberapa upaya telah dilakukan di dalam meningkatkan produktivitas petani lewat pengembangan dan fasilitas produksi lainnya. Namun, pengembangan ke arah petani sebagai pelaksana kerja masih sedikit. Faktor petani sebagai penentu dalam meningkatkan produktivitas harus diprioritaskan. Hal yang dapat dilakukan adalah memperkecil pemakaian alat manual serta memilihkan teknologi yang lebih tepat [1].

Luasnya lahan yang harus dibersihkan dan pembuatan bedeng agar dapat ditanami menjadi kendala bagi petani karena hanya menggunakan cangkul. Penggunaan cangkul ini menimbulkan rasa sakit pada leher, punggung, pinggang para petani. Ukuran dan bentuk cangkul yang beraneka ragam akan terjadi ketidaksesuaian antara ukuran tubuh petani dan cangkul sehingga menyebabkan hasil tidak optimal[2]. Sebagai makhluk yang mempunyai potensi dalam berpikir akan mengembangkan dan menciptakan alat yang efisien yang bertujuan untuk menggantikan tenaga manusia [3]. Ergonomi digital sangat berpotensi sebagai teknologi tepat guna untuk sistem kerja agro industri pangan [4]. Oleh karena itu dalam melakukan pekerjaan, petani harus benar-benar memperhatikan alat yang digunakan, agar bisa bekerja dengan kondisi nyaman dan dapat terhindar dari resiko cedera pada anggota tubuh bagian atas. Fasilitas adalah hal yang sangat penting diperhatikan dalam bekerja untuk mengurangi resiko cedera [5]. Segala fasilitas yang diigunakan dalam beraktifitas maupun istirahat dengan segala kemampuan dan keterbatasan manusia baik secara fisik maupun mental sehingga dicapai suatu kualitas hidup secara keseluruhan yang lebih baik [6]. Musculoskeletal disorders (MSDs) terjadi dalam sistem jaringan otot manusia di bagian belakang, pergelangan, lutut, dan/atau pundak dan risiko dapat meningkat akibat dari kegiatan yang dilakukan dengan postur janggal, pemaksaan yang berlebihan dan dilakukan secara terus-menerus dalam posisi yang lama. Hal ini dapat terjadi akibat dari desain tempat kerja, tugas dan/atau peralatan yang kurang baik [7]. Pekerja harus memahami sifat dan faktor risiko dari MSD tersebut untuk bisa terhidar dari MSDs ini. Menurut data Bureau of Labor Statistics (BLS) di tahun 2013 kasus MSD pada pekerja termasuk yang besar, yakni 33\% [8] . Analisis awal dilakukan dengan Rapid Entire Body Assessment (REBA) yaitu metode dalam bidang ergonomi yang digunakan secara cepat untuk menilai postur leher, punggung, lengan, pergelangan tangan dan kaki seorang pekerja. Pekerja yang menggunakan cangkul sebagai fasilitas atau alat bantu untuk membersihkan dan membuat bedeng. Dengan melakukan asesmen dengan REBA, hasil penilaiannya adalah resiko levelnya sangat tinggi dan tindakan perbaikan 
perlu saat ini juga. Pelaksanaan kegiatan ini bertujuan untuk melakukan perbaikan terhadap fasilitas yang digunakan sekarang sehingga dapat mengurangi resiko sakit dan bahkan cedera pada leher, punggung, lengan serta pergelangan tangan dan kaki (musculoskeletal disorders).

METODE PELAKSANAAN KEGIATAN Waktu dan Tempat

Kegiatan Program Kemitraan Masyarakat (PKM) Kube Usaho Basamo ini berlokasi di Jorong Koto Gadang Kanagarian Koto Tinggi Kecamatan Baso Kabupaten Agam Sumatera Barat. Kube Usaho Basamo merupakan partisipan yang digunakan dalam program PKM ini.

\section{Partisipan}

Angggota Kube sebanyak 10 orang ini pada awalnya dilakukan wawancara untuk mengetahui bagian yang dirasakan dengan menggunakan cangkul.

\section{Bahan dan Alat}

Bahan awal adalah dengan mengisi kuesioner Nordic Body Map (Quesioner NBM). Selanjutnya dilakukan asesmen dari foto pekerja dengan menggunakan cangkul dan mengukur berapa derajat leher, kepala dan pinggang dalam kondisi membungkuk, seperti pada gambar 1 berikut:

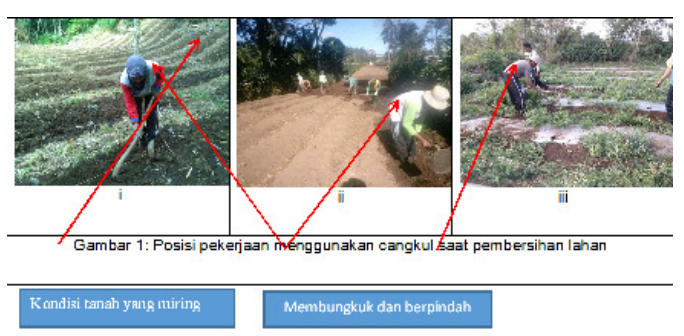

Gambar 1: Posisi pekerjaan menggunakan cangkul saat pembersihan lahan

Dengan menggunakan REBA yaitu metode dalam bidang ergonomi yang digunakan secara cepat untuk menilai postur leher, punggung, lengan, pergelangan tangan dan kaki seorang pekerja. Hasil penilaian kondisi pekerja sekarang berada pada skor 10 seperti terlihat pada gambar 2 yang artinya resiko levelnya sangat tinggi dan tindakan perbaikan perlu saat ini juga.

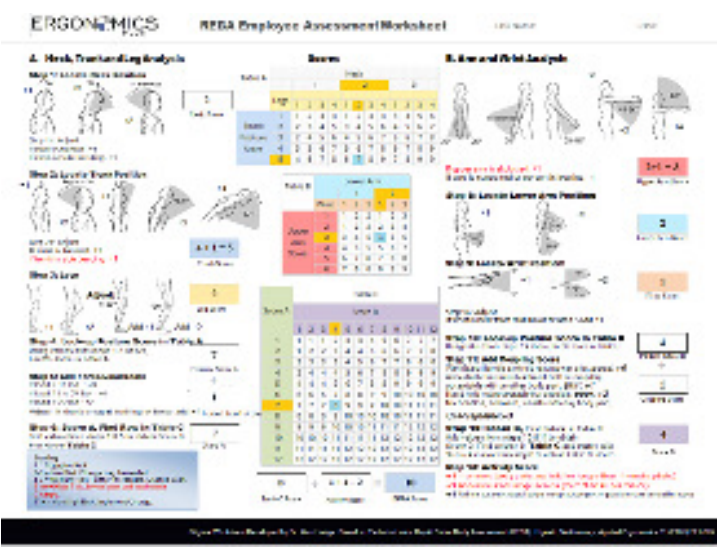

Gambar 2: Penilaian postur kerja dengan REBA

Sesuai dengan definisi ergonomi yaitu ilmu tentang manusia dalam usaha untuk meningkatkan kenyamanan di lingkungan kerja [9] dan ergonomi adalah praktek dalam mendesain peraltan dan rincian pekerjaan sesuai dengan kapabilitas pekerja dengan tujuan untuk mencegah cidera pada pekerja [10]. Hasil akhir dari sistem kerja yang ergonomis adalah meningkatnya pendapatan suatu perusahaan dan mengurangi pengeluaran (walaupun pada awalnya perlu investasi ergonomi). Untuk para petani penerapan ergonomi dapat mengurangi sering 
liburnya bekerja karena risiko cedera pada anggota tubuh akibat penggunaan alat pertanian yang tidak aman bagi pekerja. Dengan demikian rancangan sistem kerja dengan tingkat ergonomi yang baik berarti juga memiliki aspek ekonomi yang baik.

Keefektifan alat bantu merupakan hal yang paling penting dalam melakukan suatu pekerjaan. Adakalanya dalam melakukan suatu pekerjaan dengan menggunakan alat bantu yang tidak tepat akan berdampak pada ketidaknyamanan pekerja bahkan akan menimbulkan resiko atau cedera pada pekerja ,produktivitas produksi akan menurun dan lain sebagainya. Penggunaan alat bantu yang tepat akan dapat mempercepat proses dan memperingan beban kerja [11]. Aktivitas kerja manual yang tidak memperhatikan faktor kenyamanan akan mempengaruhi efektifitas, efisiensi dan produktivitas kerja [12].

\section{Metode}

Ada 3 alat yang diusulkan untuk memperbaiki posisi kerja dengan alat bantu atau fasilitas yang akan digunakan. Pemilihan alat ini didiskusikan dengan anggota Kube dengan kriteria alat tersebut akan mengurangi resiko cedera pada para petani, kemudian alat tersebut dapat mempercepat kerja serta alat tersebut mempunyai fungsi lain yang sangat membantu para petani. Alat yang diusulkan adalah gear box weeder yang dimodifikasi, mesin pemotong rumput dan cultivator.

\section{HASIL DAN PEMBAHASAN}

Hasil diskusi berdasarkan kriteria yang ditetapkan diawal akhirnya cultivator adalah alat yang dipilih. Karena alat ini tidak digunakan dengan posisi membungkuk, dapat lebih cepat untuk membersihkan lahan dan fungsi lainnya bisa langsung digunakan untuk membuat bedeng. Selanjutnya dengan pemilihan cultivator ini akan dilakukan lagi asesmen terhadap anggota tubuh pekerja. Pekerja menggunakan cultivator lalu difoto dan dihitung kembali posisi kerja seperti pada gambar 3:

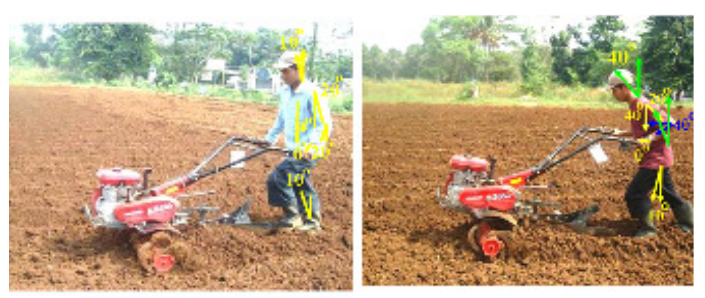

Gambar 3: Posisi pekerja dengan menggunakan cultivator

Berdasarkan gambar 3 diatas dilakukan kembali asesmen dengan REBA seperti pada gambar 4 berikut:

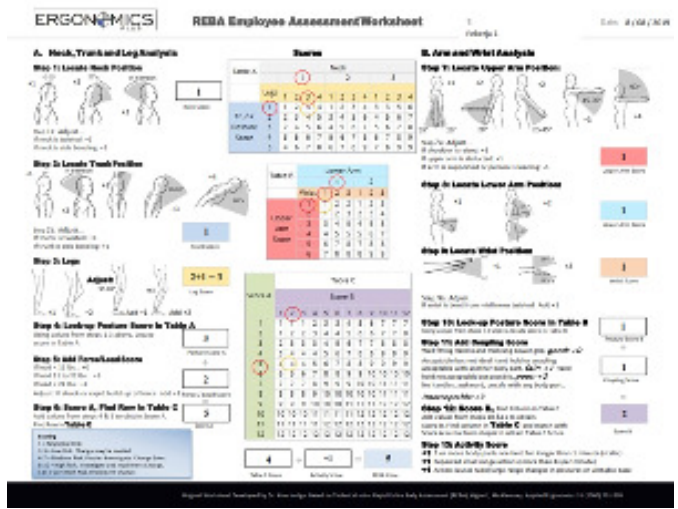

Gambar 4: Perhitungan REBA saat petani menggunakan cultivator

Skor aktivitas diperoleh dengan nilai 5 yang artinya berada pada level sedang dan masih perlu dilakukan perbaikan. Berbeda 
dengan menggunakan cangkul tadi berada skor 10 yaitu pada level tinggi dan perlu segera diperbaiki.

Upaya keberlanjutan yang dapat dilakukan adalah melakukan modifikasi terhadap cultivator seperti pemilihan bahan yang ringan sehingga tidak terlalu berat untuk dipergunakan. Namun sebaliknya dampak yang terlihat dari penggunaan cultivator ini adalah semakin cepat kerja dalam pembersihan dan pembuatan bedeng. Sekaligus ini dapat menurunkan biaya atau upah pada tenaga kerja.

\section{KESIMPULAN}

Posisi pekerja menggunakan alat tidak lagi membungkuk seperti saat pekerja menggunakan cangkul. Dengan menggunakan cangkul ditemukan beberapa posisi yang sangat beresiko cedera pada bagian punggung (low back pain), pinggang, dan leher. Cultivator ini untuk resiko punggung tidak lagi membungkuk sehingga bisa terhindar dari resiko cedera pada MSDs. Jika diganti dengan teknologi yang telah tersedia jumlah lahan yang digarap bisa lebih banyak. Ini berdampak langsung terhadap jumlah tanah yang bisa digarap dan diharapkan juga terjadinya peningkatan hasil produksi.

Diharapkan setelah tersedianya alat ini nantinya diharapkan jumlah lahan yang akan digarap lebih banyak dari kondisi sekarang. Alat ini akan diserahkan kepada KUBE dan pemakaian dapat digunakan secara berganti dengan anggota yang ada. Sistem yang digunakan bisa dengan sistem sewa dan nanti biaya sewa bisa dijadikan sebagai aset kelompok yang akan digunakan untuk maintenance alat.

\section{UCAPAN TERIMAKASIH}

Kegiatan PKM ini dibiayai melalui program Hibah Program Kemitraan Masyarakat Kemenristekdikti tahun 2019 Oleh karena itu, kami sebagai pelaksana kegiatan PKM mengucapkan terima kasih yang sebesar-besarnya kepada Kemenristekdikti. Rasa syukur dan apresiasi yang tinggi juga kami sampaikan kepada Kube Usaho Basamo Jorong Koto Gadang yang mau bekerjasama dengan kami TIM PKM Fakultas Teknologi Industri Universitas Bung Hatta beserta segenap warga yang terlibat dan mendukung kegiatan ini dari awal hingga akhir. Selain itu kami juga mengucapkan terima kasih atas bantuan tenaga, waktu, dan pikiran yang dicurahkan dari rekan-rekan dosen dan mahasiswa program studi Teknik Industri yang terlibat dalam kegiatan ini.

\section{DAFTAR PUSTAKA}

[1] Sucipta, I Nyoman., Agro Ergonomi: Dasar-Dasar Ergonomi Di Bidang Pertanian, 2009, Udayana University Press.

[2] Purwanto, Wahyu., Perancangan Cangkul Ergonomis Untuk Meningkatkan Kapasitas Kerja Petani Dalam Mengolah Tanah Sawah, 1992, Agritech: Jurnal Fakultas Teknologi Pertanian Ugm.

[3] Rambe, Robi Salim, Achwil Putra Munir, Saipul Bahri Daulay., 2017, Analisis Ergonomi Terhadap Ruang Kendali Pada 
Traktor Roda Empat Kinta Sb55, J.Rekayasa Pangan Dan Pert., Vol.5 No. 2 Th. 2017.

[4] Ushada, Mirwan., 2019, Kajian Potensi Ergonomi Digital Untuk Mendukung Sistem Kerja Agroindustri Pangan, Jurnal Teknologi Dan Industri Pertanian Indonesia, Universitas Syiah Kuala.

[5] Mufti, Dessi., Aidil Ikhsan, Tri Marta Putri., 2019, Workplace Ergonomic Risk Assessment Toward Small-Scale Household Business, Iop Conference Series: Materials Science And Engineering.

[6] Tarwaka. Dasar-Dasar Pengetahuan Ergonomi Dan Aplikasi Di Tempat Kerja. Surakarta : Harapan Press; 2013. $137 \mathrm{P}$

[7] Chaffin,R.,Lemieux,A.,\&Chen,C.(2006). Spontaneity And Creativity In Highly Practiced Performance. In I. Deliège \&
G.A. Wiggins. Musical Creativity: Multidisciplinary Research In Theory And Practice (Pp. 200-218). London: Psychology Press.

[9] Nurmianto, Eko. 1996. Ergonomi:

Konsep Dasar Dan Aplikasinya, Surabaya, Guna Widya.

[10] Osha Training Institute. (2006). Safety And Health Programs (Online) Https://Www.Osha.Gov/Dte/Grant_Mate rials/Fy08/Sh-17815. 08/03_Pg_Module_3.Pdf (20 Oktober 2016).

[11] Wignjosoebroto, Sritomo, 2008. Ergonomi, Studi Gerak Dan Waktu. Penerbit Guna Widya.

[12] Jovianto, 2005, Kajian Ergonomi Dalam Perancangan Alat Bantu Proses Penyetelan Dan Pengelasan Produk Tangki Travo 